\title{
Reframing the effectiveness of feedback in improving teaching and learning achievement
}

\author{
Anne Malar Selvaraj, Hazita Azman \\ Faculty of Social Sciences and Humanities, Universiti Kebangsaan Malaysia, Malaysia
}

\begin{tabular}{l} 
Article Info \\
\hline Article history: \\
Received Apr 7, 2020 \\
Revised Sep 31, 2020 \\
Accepted Oct 13, 2020 \\
\hline
\end{tabular}

\section{Keywords:}

Developmental feedback

Feedback enhanced instruction

Pupils' feedback

Teaching and learning

Transforming assessment

\begin{abstract}
Student feedback is established as an imperative learning and teaching technique, but feedback from students is less likely. The potential of feedback to boost learning outcomes refers to scholarly writing and is considered together as one of the most impressive methods for enhancing the success of students. In education, there is, nevertheless a lack of clarification about what feedback means and far less clarification on how one should interpret it. Feedback guides students to learn and supports them in order to achieve the aim of the lesson. The goal of this paper is to discuss teacherwritten reviews and obstacles to student feedback in order to recognise the usefulness of feedback in the education domain. Feedback from students illustrates the comprehensions, boundaries and features that knowledge should be compiled and employed to establish work or learning approach. The assessment study renders the appropriate feedback, and, in this manner, the students learn how to accomplish their learning goals. While feedback is not exclusively evaluated, these are the essential ingredients of making evaluation a mechanism for teachers' and students' future learning.
\end{abstract}

This is an open access article under the CC BY-SA license.



\section{Corresponding Author:}

Anne Malar Selvaraj,

Faculty of Social Sciences and Humanities,

Universiti Kebangsaan Malaysia,

43600 UKM Bangi, Selangor, Malaysia.

Email: p94586@siswa.ukm.edu.my

\section{INTRODUCTION}

Feedback is recognised as an indispensable component in writing and functions as the core pedagogical educational tool. Its vital position was derived from an approach to process writing in the 1980s, and input was used as one of the grounds of formative evaluation in the 1990s. Black and Wiliam [1] suggested that feedback information could be used to boost their learning in order to be developmental. Sadler [2] maintained that the learning gap knowledge between real and reference levels is treated only as feedback as used to transform the learning difference. In consideration of the feasibility of developmental feedback through the process of learning, feedback-enhanced lessons were introduced at the least instructive level in its comprehensive levels of data [3], comprising writing instructions, in every single branch of data. In the first language (L1) or the second language (L2), teaching writing is a complex task, and formative input has become a primary concern of every teacher.

Giving importance and responding to students are an integral aspect of the learning to write process. The ultimate assistance of learning to write is the access of students to educator's input and their effective management of the feedback [4]. If written classes do not entail feedback or if students cannot obtain input or output from the teacher as they write, it is unpropitious to promote a successful writing capacity. A remarkable study community in the fields of learning recorded the weight of the teacher's written reviews. 
The pertinence of the written input of teachers is recognised by teachers and students in all English language environments, especially in classrooms where writing is process oriented. Furthermore, it allows students to evaluate themselves while also encourages them to advance the process of learning to write step by step $[4,5]$. Teachers aim to use effective strategies in these contexts to respond accordingly to the writings of their students to help them build writing expertise. Nonetheless, teachers teach writing in order to adopt a product-driven approach circumstances for two primary reasons. It is because some of them are essentially ignorant of the form of teaching writing and for larger circle, it is because of the strict time-based syllabus, the item-designed appraisal system and the big-class scale. Hence, they must use the product approach with those constraints. These are several of the teacher's requirements during the teaching and learning process in the classrooms.

Teachers offer written reviews to students in order to further improve their learning. In both cases, there is a concern where students typically do not receive input and respond in the manner desired [5, 6]. Researchers attempted to distinguish characteristics or variables to address this problem that improves feedback soundness [7, 8]. An understanding of the writing process implies an overview of linguistic skills and an appreciation of the feedback phase, which includes an insight into student engagement. The domain of language evaluation is a field that seeks to understand the section of language information and, hence, the role of the student in the feedback process. In the field of language evaluation [9], the quality comprehension of the language used to provide knowledge, and its idea [10,11] was examined. Feedback was identified as an imperative learning strategy by the assessing advocates for formative goals, and demonstrated the processes used in the formative feedback affair throughout this process.

In the formative evaluation field, therefore, perspective is presented into components which impacts the feedback process, as an example, the attributes of students and student alternatives [10, 11]. The principle of legitimacy is in line with assessments for formative purposes, and input is also a benefit to the evaluation field. If feedback aims to teach effectively, then there is a need to examine, whether this is significant to any researcher or practitioner. Feedback is a crucial concept in education, learning and evaluation. In education, it is also defined as data provided by an agent concerning facets of the success of understanding of the student's achievement [12]. Feedback is also rendered by diverse mechanisms, such as students may provide peers with oral feedback, and a computer program may furnish a student with computerised feedback. Over the years, various studies $[9,11,12]$ confirmed the need to give emphasis on how the students respond to feedback. In other words, it is necessary to give attention to how students receive, interpret and employ feedback rather than how teachers deliver it.

Teachers should promote students to identify the extent of their awareness (their learning goals status and appraisal criteria) while offering more knowledge at a comparable period to help bridge the learning gap between their real and desired levels. Many researches suggested [12-14] that feedback in the form of comments might motivate students to recognise their work's strengths and limitations and benefit from progress. It could be because feedback does not address a concern if the student's learning process is not well thought out, structured and carefully managed. It would usually be vague, poorly distributed and therefore, barely help students' comprehension. As Sadler [2] pointed out, the standard of feedback exceeds the volume. It is, therefore, quintessential that teachers recognise what strengths progress and improve learning, and what barriers they encounter in writing feedback.

A study of formative assessment and learning studies, Black and William [1] argued that feedback increased potential as: 1) it focused on specific errors and less acceptable methods, and proposed ways in which students could enhance their performance; 2) rehabilitated mix-ups and allowed students to analyse critically; 3) recommended just what is significant for students to respond independently; 4) motivated the search for elective solutions; 5) highlighted continuous process more than on product, and 6) is employed effectively. One system for furnishing feedback is utilising written comments. The most notable benefit of this type of analysis is that teachers can have more time. By applying these approaches, therefore, they can review students' work in detail and points result from a more informed consideration. Thus, this paper focused on the benefits of applying written feedback as a primary component in transforming assessment into a tool for future teaching and learning achievement for teachers and students.

\section{LITERATURE REVIEW}

Feedback is never a separate action in the learning process as the time spent learning. It is typically structured within the framework of the evaluation and formative evaluation. The critical role of formative evaluation is to strengthen, update and improve student learning, as maintained by Wiliam and Thompson [7]. Formative assessment encourages learners to narrow the distance between where they are and where they should work in their learning. It gives pupils input on their learning and facilitates them to control their thoughts or behaviour. It opposes a summative evaluation or assessment [14] which intends to conclude 
the result or understanding of students at the end of a learning unit. After all considerations; summative appraisals can also be considered formative if they furnish feedback which students can use in future assessments. For formative evaluation, Hattie and Timperley [8] are the key proponents of feedback for formative assessment framework. They revealed that robust formative evaluation is related to three primary investigations: 1) where am I going?; 2) how am I going?; and 3) where to next? There are only a few discrepancies, as the results usually indicate that input is increasingly enthralling if, it associates with a learning goal or objective.

Gee [15] affirms that writing is often used as a mechanism for thinking when students write, share their feelings, do reflections and thoughts. They learn how to understand themselves and, at the same time, understand the emotions, perceptions and opinions of others. Individuals, in any situation, strive to grasp who they are when they write. The "character" inherent in writing may also influence the learning of languages, as the process of language learning may be restricted or encouraged according to the students' importance or possible interest in the education atmosphere [16]. Writing, therefore, is an imminent form of interaction, contemplation and learning. The value of writing implies that teachers hold a quintessential task: to teach writing. It is an arduous capacity for teachers to teach, however, and it is an onerous task for students to excel.

Many experts [16, 17] suggested acknowledged feedback practices to meet the challenging nature of feedback. Ferris [17] offered an outline of best practice for reviews. It contains a broad scope of emphasis in both written and oral comments (content, organization, language, mechanics, style), such as structured input, explicit and indirect mistakes correction for long term benefit, feedback on multiple drafts, feedback on multiple sources, and conferencing with students. Many of these best feedback practices represent elementary feedback expectations in the formative evaluation. The end question is to ensure, through the resubmission of content for a new evaluation [3, 18], that students will be able to use feedback. Accordingly, Lee [19] noted the need for resubmissions because writing tests appear to concentrate more on teachers and students than on their formative ability.

The recognition of written reviews resulted in a more significant curiosity in researching this topic [17, 20-22]. Nonetheless, feedback studies that rely on theories of formative evaluation are still scarce. Lee and Coniam administered Asian studies $[19,23]$ and reported that evaluation and feedback are provided in single draft format and ultimately satisfy summative requirements. Lee and Coniam [23] in their research suggested the teachers' need to lookout for more related resources for successful structured evaluation. Additional studies are available in writing on formative and feedback formative evaluation pedagogy [24]. Many suggested that the evaluation and feedback must change according to the formative evaluation, and Burner's intervention study [25] demonstrated progress in self-assessment and peer review and thus addressed the central importance of error correction. Burner [25] revealed a lack of straightforward application of formative evaluation concepts and a deficiency of students' comprehension of individual elements.

Feedback is used in schools in the form of written comments. Major studies led to the multiple variables, e.g. strategy (time, length, public) and content (focus, feature, valence, lucidity, clearness, tone), which regulate the feasibility of feedback. Although the results were not entirely undeniable, there are four points that are significant: 1) feedback must address the necessities of the students; 2) feedback must be timely; 3) feedback must be clear and straightforward; and 4) feedback should concentrate on the task processes instead of on the individual $[18,21,26]$.

Concerning writing reviews, Bruno and Santos [27] agreed that comments must be simple, structured, include a commonplace and basic jargon, and refrain from providing some portion of the acknowledgement. Regan [28] perceived the tone in which written input is passed as needing to be taken into account. It is critical because teachers must strike a balance among enabling students to make significant improvements and inspiring them to make it. Moreover, written feedback is frustrating and daunting. It is likely to lead to students not being vigilant or demotivated by the magnitude of the improvements to be made. Thus, when providing written feedback, teachers must be precise and more straightforward [28].

By taking into account the input of educators, former studies [4, 29] highlighted several characteristics of positive and useful feedback. Feedback must be reader-based and criterion-based. It must inform the student whether writing meets the intended target of communication. It should not only discuss the clarity of communication and arrangement of concepts but also show the students the effect of writing on the reader. This affirms the assurance of students as authors and builds confidence in order to strengthen their writing. Instead, it should present advice for future work, instead of having students feel responsible for writing, and then, the feedback should be insightful. Feedback should be in the form of observations, and open-ended questions as it empowers the students to consider adequate approaches to enhancing the draft, it too, should be constructive, supportive feedback, straightforward and easy [30]. Thus, the success measure of feedback must be straightforward for students. 
Feedback rendered as a central feature of formative evaluation guides students to integrate their qualities, recognise their weaknesses [31] and facilitates them in the actions necessary to achieve their learning results. Nevertheless, the formative assessment must have consistent characteristics to improve learning and reach a higher degree of achievement in cognitive and competence outputs. Race [32] explored and revealed these principal feedback attributes:

a. Timely: If feedback is timely, students will assess how their roles have been measured. It is also vital that the feedback timeline is effectively communicated to students, which permits students to use feedback for potential learning and evaluations.

b. Motivational: Feedback can influence student motivation and trust positively or negatively. It triggers the emotions of students and affects their contribution to the learning process. The formative evaluation shall then be inspiring and useful to encourage and motivate students.

c. Individual/Personal: The increase of students' performance should reflect in their learning process. For this reason, formative feedback must match the performance of all students in order to develop their abilities. It should be adapted and tailored to the strengths and limitations of individual students.

d. Manageable: Feedback needs to be specific to ensure students recognise their qualities and weaknesses. Nonetheless, too complicated comments and feedback formats can lead to students being overwhelmed and challenging to separate relevant feedback.

Directly linked to evaluation criteria/learning outcomes: evaluation criteria define specific and unequivocal performance expectations and must be identified with the learning results of a course. As the standards for assessment set out what students needed to do so, a formative evaluation should increase the level to which the student complies, acknowledges learning differences and discusses clear errors and hypotheses [32]. Learners need to receive continuous feedback. Students with a positive attitude may then see feedback as a tool for advancement, whereas those with a negative attitude may then perceive it as a hindrance. Therefore, the quality of formative assessment should also succeed in sharing with the students in empowering and ensuring that the content of feedback is used for student preparation to further advance in their learning.

In regard to the instructional reason for the teacher's written response to students' writing, analysis within the fields of writing distinguishes between formative and summative feedback. While the former is intended to help students review their work before it is evaluated, the latter assesses the quality of the product completed [33]. Whether it is formative or summative, regardless of the instructive reason for the written feedback of the teachers, it indeed owns various emphasis. It can be a structure (centered on the revision of punctuation), content-based (concentrated on quality and association of substance), or integrative (a combination of both). With this distinction in mind, the content that is based on the process approach, the focus of the teacher input needs to be drafted and followed by a structure concentrated feedback as the final draft. While some studies revealed that students are increasingly leveraging structure-based feedback, other studies reported the tendency of students to obtain substance-based feedback and to increase their motivation $[11,33]$.

Further, extensive feedback can cause students to change everything with trial and error strategies without considering the relationship between direction, feedback and the expected learning. Comments must be decipherable (simple to read), use basic jargon (words and phrases students know) and maintain a strategic distance from abbreviations or symbols because students cannot grasp them. The illegibility of feedback deprives students of their capacity to understand themselves, so suggestions should be transparent for students. Comments with such details on academic terms must be mainly published, although caution is required to ensure that students understand the entire message. Students acknowledge clear, unequivocal and motivating feedback $[11,33]$. They understand how to interpret and apply it along these lines.

On a study conducted by Weaver [34], students acknowledged the four feedback features they thought were unfit for improving learning. These characteristics are excessive or questionable insights which required guidance, centered on the ineffective criteria to evaluate them. Comments should then be realistic, context-dependent and identified with the work of the students. It should also be equivalent to the previous knowledge and information about the knowledge of students. That explains why it is so critical to know students well for this reason. There is also evidence that comments offering adjustment techniques may be of specific benefit to students. Students should adjust their work and make changes to achieve long-term learning. In any event, it is vital to give students some tips to realise how they can revise and enhance their work. In order to do so, the teachers must describe what is necessary to accomplish the target. They inspire students to improve more in their learning. Feedback must elevate learning, so teachers should avoid harsh, offensive words as this can impede the pupil's improvement [35].

It was discovered in the literature $[1,18,36]$ that evaluation for learning is crucial not only for students but also to teachers. The reflection on feedback helps one to think about what happens at that moment and what could happen later on. It facilitates one to respond to experience, develop teaching 
strategies, and give the classroom a robust notion [37]. If effectively practised, feedback will enhance teaching and learning exercises to overcome students' challenges. By reflecting on the teacher's understanding, they provide input that shows where the priority and focus of teaching are to be given [18, 37]. It improves learning in the classroom as teachers can change their lessons based on feedback. Besides, feedback helps teachers to create models of learning and knowledge for their students in order to guide future teaching and feedback.

Teachers, therefore, need to be trained as effective feedback providers and will need plenty of feedback from their colleagues on their use of feedback. Questions are one way for teachers to establish their feedback plans. Cohen [38] noted that feedback must be helpful and manageable, must be communicated to students where performance standards are met so that feedback contributes to enhanced learning. Feedback is also a means of elevating teaching skills with colleagues. The teachers decide on feedback as a priority to enhance formative feedback practices and therefore, share their students' feedback with comments and suggestions from their colleagues during meetings [30, 38]. They may also evaluate items used to enhance teacher's feedback and address whether or not the feedback contributed to significant results, and if not, what feedback might have become increasingly more beneficial.

Feedback research aimed at exploring the effect of the written comments of teachers on students' writing during the learning to write process considering the feedback from teachers as an essential tool to help learners to do revision [17, 38] and alter their draft texts. Feedback studies unveiled that written feedback from teachers on final writing is inadequate because students never consider it after they got their grades. In this way, finding out how to write in second language classes is increasingly beneficial in order to allow students to develop their writing more promptly. Studies in this context focused on students' feedback and agreed on the reactions of students to teacher feedback as relevant to support the development of feedback practices by teachers. Various studies [39-41] on the responses of students to the feedback received by teachers noted that how students respond to their feedback can rely on the characteristics and individual needs of the student.

Besides, teachers must interact with their students on the importance of their input based on their questions. Through this activity, teachers get a broad understanding of how their feedback capacities can be strengthened and how the students can improve their understanding. It is, therefore, necessary, in order to understand them, teachers need to address the significance of the comments. Consequently, written input can be improved by discourse. The method of contact should be two separate ways [42-44], between teacher and student, with the aim for the teacher to explain when feedback is not clearly communicated and why it is not significant. Teachers must examine the comments made concerning previous and recent work to identify the features of comments that support the process of learning and those that did not contribute to the changes made to this task.

\section{RESEARCH METHOD}

Since the aim of this study was to relate the effectiveness of feedback in improving teaching and learning achievement, the literature for analysis was searched and selected based on several keywords, specifically the effectiveness of feedback in the education domain, secondary school and academic performance. The papers were sourced from several databases such as Elsevier, Google Scholar, ERIC, and other Scopus-indexed journals.

\section{RESULTS}

Based on the meta-analysis conducted, teachers' developmental feedback played an important key in assisting students to accomplish their learning goals and improve their learning performance. Therefore, it is important that teachers provide effective feedback continuously and encourage students to accelerate their learning achievement as a mechanism for future learning. The findings are summarised and elucidated in Table 1 . 
Table 1. A meta-analysis of teachers' feedback and students' learning achievement

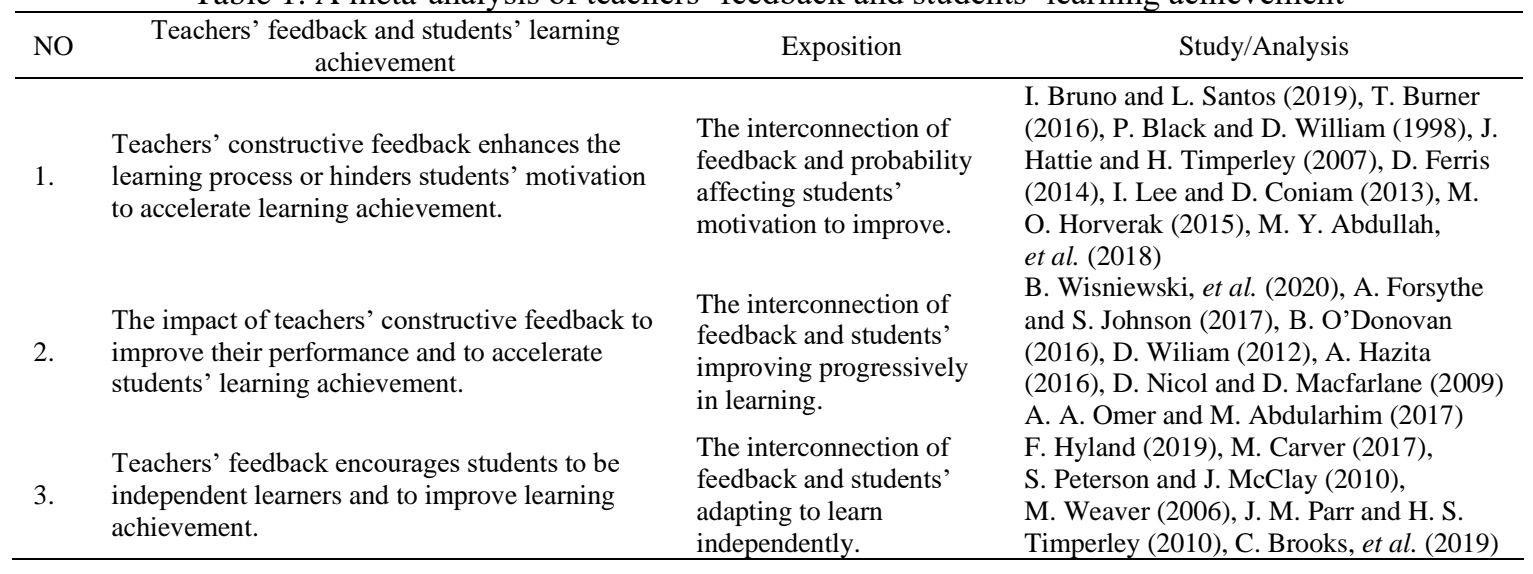

The studies in the meta-analysis concentrated in investigating the positive impact of teachers' feedback as a primary component in improving teaching and learning achievement. The results revealed that teachers feedback have some impact in students learning achievement in the scope of: 1) affecting students' motivation to improve; 2) improving progressively in learning; and, 3) adapting to learn independently.

\section{DISCUSSION}

Teachers' feedback provides compelling insights [45] of the importance of learner's strengths, points out clearly on how to develop them and provide opportunities to improve their work in order to accelerate learning. Based on the meta-analysis, the interconnection of feedback is positively correlated with student's academic achievement. It is crucial that students are given continuous construction feedback for improvement for personal development in their work so that they can become independent learners in their future learning to move forward confidently. It is important to note that, teachers' feedback has weakness, therefore, teachers' must be responsive of students' prior knowledge and feelings.

Even though the interconnection of feedback is positively connected with how well students perform in their learning, previous research [46, 47] also points out that feedback can have its negative effects as well. This is because the efficacy of feedback, relies on the correct information provided by teachers on each student's difficulties, skills and nature in a specific case. Literature points out clearly, that this process is complicated, complex and repetitive in nature. Nevertheless, cohesive collaboration can help to achieve this mission, teachers should include whatever choice to be made, they will never be certain that input will support and accelerate the process of learning. On the other hand, students' progress is linked to strengthen their weakness and reciprocally to improve their performance in order to accelerate their learning. The fact is this process can be time consuming as there are positive and negative consequences.

The analysed literature also points out $[48,49]$ the weakness of feedback when teachers are often not very conscious of their effectiveness in assessing their students to improve learning. Teachers must reflect on their teaching practices in order to better their experience and teaching. Teachers established time constraints that hindered the class' pertinent cultures in developing formative evaluation. Formative assessment was useful for teachers, but the communication in that context was a challenge, as students were expected to master tasks and skills. Teachers' need to build their confidence and motivation so that, they can achieve better academic progress with their students.

In addition, it is a callous process to write comments because the form and content must help students find ways to solve their errors, and yet they do not have a response. It is known that teachers' face difficulties in writing feedback based on each student's unique characteristics. Every situation is an alternate case, explicit and singular. Teachers should strive to know their tendencies and mentality, which are similar to feedback, how they use them and why they select a few strategies, not others, to understand and motivate students. Teachers need to be clear of how to overcome these barriers to help students in their learning, though, it is difficult, but it can be done with hard work [50, 51]. Nevertheless, students need the right direction and advice on how they can express feedback confidently. They need to comprehend that feedback improves their own self-improvement in enhancing their own learning. Students' need to be aware that in order to improve learning, they need to adopt a positive culture of giving and receiving feedback from their teachers. If this can be established clearly by the teacher and digested positively by the students', feedback can be a powerful tool in enhancing and accelerating the learning process. 
With reference to teachers' feedback, future studies might include the participation of secondary and primary schools from each state to enable the researchers to investigate different factors which relate to effective feedback credibility as an important learning tool in improving students' learning achievement.

\section{CONCLUSION}

The key principles of enhancing students learning experience has been discussed in the reviewed literature. The analysis revealed that the feedback given by teachers must not only be instructive but should also bear in mind the context, motivation, ability to learn and inclinations of students. It too, must render positive formative feedback and ensure the participation and advancement of learning by students. Positive feedback on evaluation criteria should be prompt, inspiring, tailored, responsive and specific. Additionally, a strategic communication approach is needed to ensure that students are linked to the feedback material. Relevant feedback reliability characteristics may also be tested on the feasibility of the advanced technique. Teacher feedback holds a distinctive difference in formative evaluation, and teacher feedback offers students valuable knowledge on what they do and know, and what they need to do at the next level. Students' who see that they have the knowledge, must develop it and continue to learn. Along these lines, the secret to enriched comprehension and creativity can be great feedback. Ergo, formative assessment is a quintessential part of the learning process since it endeavours to contribute to effective learning. Feedback is indeed a mechanism to assist students to respond to their problems in their learning. Therefore, feedback should concentrate on the fundamental aspects of progress and support the students with adequate knowledge so that the learning and achievement process can be enhanced progressively.

\section{ACKNOWLEDGEMENTS}

The authors are very grateful to the experts for their constructive feedback and suggestions to enhance this journal.

\section{REFERENCES}

[1] P. Black and D. Wiliam, "Assessment and classroom learning. Assessment in Education," Principles, Policy and Practice, vol. 5, no. 1, pp. 7-74, 1998.

[2] R. Sadler, "Formative assessment and the design of instructional systems," Instructional Science, vol. 18, pp. 119-144, 1989. [Online]. Available: https://doi.org/10.1007/BF00117714

[3] R. Sadler, "Formative assessment: Revisiting the theory," Assessment in Education: Principles, Policy and Practice, vol. 5, no. 1, pp. 77-84, 1998.

[4] S. Peterson and J. McClay, "Assessing and providing feedback for student writing in Canadian classrooms," Assessing Writing, vol. 15, no. 2, pp. 86-99, 2010.

[5] B. O' Donovan, et al., "A scholarly approach to solving the feedback dilemma in practice," Assessment \& Evaluation in Higher Education, vol. 41, no. 6, pp. 938-949, 2016.

[6] D. Wiliam, "Feedback: Part of a system," Educational Leadership, vol. 70, no. 1, pp. 30-34, 2012.

[7] D. Wiliam and M. Thompson, "Integrating assessment with instruction: What will it take to make it work?" in C.A. Dwyer (Ed.), The future of assessment: Shaping teaching and learning. Mahwah, NJ: Erlbaum, pp. 53-82, 2017.

[8] J. Hattie and H. Timperley, "The power of feedback," Review of Educational Research, vol. 77, no. 1, pp. 81-112, 2007.

[9] L. F. Bachman and A.S. Palmer, Language assessment in practice: developing language assessments and justifying their use in the real world. Oxford: Oxford University Press, 2019.

[10] G. Stobart, "Validity in Formative Assessment," In J. Gardner (Ed.), Assessment and learning, 2nd ed. London: Sage Publications, pp. 233-242, 2014.

[11] D. Wiliam and S. Leahy, Embedding Formative Assessment: Practical Techniques for K-12 Classrooms. West Palm Beach, FL: Learning Sciences International, 2015.

[12] S. M. Gamlem and K. Smith, "Student perceptions of classroom feedback," Assessment in Education: Principles, Policy \& Practice, vol. 20, no. 2, pp. 150-169, 2013.

[13] S. M. Brookhart, How to give effective feedback to your students, 2nd ed. Alexandria, VA: ASCD, 2017.

[14] C. B. Dean, et al., Classroom instruction that works research-based strategies for increasing student achievement, 2nd ed. Alexandria, VA: ASCD, 2012.

[15] J. P. Gee, Social Linguistics and Literacies: Ideology in discourses, 2nd ed. London: Falmer, 2008.

[16] K. Hyland and F. Hyland, "Interpersonal aspects of response: Constructing and interpreting teacher written feedback," in K. Hyland \& F. Hyland (Eds.), Feedback in ESL writing: Contexts and issues. Cambridge: Cambridge University Press, pp. 206-224, 2015.

[17] D. Ferris, "Responding to student writing: Teachers' philosophies and practices," Assessing Writing, vol. 19, pp. 6-23, Jan. 2014

[18] D. Nicol and D. Macfarlane-Dick, "Formative Assessment and Self-regulated Learning: A Model and Seven Principles of Good Feedback Practice,” Studies in Higher Education, vol. 31, no. 2, pp.199-218, 2009. 
[19] I. Lee, "Feedback in Hong Kong secondary writing classroom: Assessment for learning or assessment of learning?" Assessing Writing, vol. 12, no. 3, pp. 180-198, 2007.

[20] F. Hyland, "Focusing on form: Student engagement with teacher feedback," System, vol. 31, no. 2, pp. 217-230, 2019.

[21] J. M. Parr and H. S. Timperley, "Feedback to writing, assessment for teaching and learning and student progress," Assessing Writing, vol. 15, no. 2, pp. 68-85, 2010.

[22] A. Jonsson, "Facilitating productive use of feedback in higher education," Active Learning in Higher Education, vol. 14, no. 1, pp. 63-76, 2013.

[23] I. Lee and D. Coniam, "Introducing assessment for learning for EFL writing in an assessment of learning examination-driven system in Hong Kong," Journal of Second Language Writing, vol. 22, no. 1, pp. 34-50, 2013.

[24] M. O. Horverak, "Feedback practices in English in Norwegian upper secondary schools," Nordic Journal of Modern Language Methodology, vol. 3, no. 2, pp. 74-9, 2015.

[25] T. Burner, "Formative assessment of writing in English as a foreign language," Scandinavian Journal of Educational Research, vol. 60, no. 6, pp. 626-648, 2016.

[26] C. Brooks, A. Carroll, R. M. Gillies, and J. Hattie, “A Matrix of Feedback for Learning," Australian Journal of Teacher Education, vol. 44, no. 4, pp. 14-32, 2019.

[27] I. Bruno and L. Santos, "Written comments as a form of feedback," Studies in Educational Evaluation, vol. 36, no. 3, pp. 111-120, 2019.

[28] P. J. Regan, "Read between the lines: the emancipatory nature of formative annotative feedback on draft assignments," Systemic Practice and Action Research, vol. 23, no. 6, pp. 453-466, 2010.

[29] K. Hyland, and F. Hyland, "Feedback on second language students writing," Language Teaching, vol. 39, no. 2, pp. 83-101, 2016.

[30] M. Heritage, Formative Assessment: Making It Happen in The Classroom. California: Corwin, 2010.

[31] G. A. Brown, et al., Assessing Student Learning in Higher Education. Routledge, London, 2013.

[32] P. Race, The Lecturer's Toolkit - A Practical Guide to Assessment, Learning and Teaching, 3rd ed. Routledge, London, 2013.

[33] M. M. P. Alamis, "Evaluating students' reactions and responses to teachers' written feedbacks," Philippine ESL Journal, vol. 5, pp. 40-57, 2010.

[34] M. Weaver, "Do students value feedback? Student perceptions of tutors' written responses," Assessment and Evaluation in Higher Education, vol. 31, no. 3, pp. 379-394, 2006.

[35] L. Goldstein, "Questions and answers about teacher written commentary and student revision: teachers and students working together," Journal of Second Language Writing, vol. 13, no. 1, pp. 63-80, 2004.

[36] P. Black and D. Wiliam, "Developing the theory of formative assessment," Educational Assessment, Evaluation and Accountability, vol. 21, no. 5, pp. 5-31, 2009.

[37] S. Carrington and J. MacArthur, Teaching in Inclusive School Communities. Milton, Qld: John Wiley \& Sons Australia, 2016

[38] A. D. Cohen, "Fedback on Writing: The Use of Verbal Report," Studies in Second Language Acquisition, vol. 13, no. 2, pp. 133-159, 2008.

[39] A. Hazita, "Implementation and Challenges of English Language Education Reform in Malaysian Primary Schools," 3L: The Southeast Asian Journal of English Language Studies, vol. 22, no. 3, pp. 65-78, 2016.

[40] D. Stone and S. Heen, Thanks for the feedback: The science and art of receiving feedback. New York, NY: Penguin, 2015.

[41] M. Hamzah and S. Paramasivam, "Between the ideal and reality: Teachers' perception of the implementation of school-based oral English assessment," The English Teacher, vol. 38, pp. 13-30, 2017.

[42] M. Y. Abdullah, et al., "The effect of peers and teachers' feedback on writing anxiety level through CMC applications," International Journal of Emerging Technologies in Learning, vol. 13, no. 11, pp. 96-207, 2018.

[43] M. Carver, "Limitations of Corrective Feedforward: A Call for Resubmission Practices to become Learningorientated," Journal of Academic Writing, vol. 7, no. 1, pp. 1-15, 2017.

[44] M. W. Othman, The Role of Feedback in Malaysian ESL Secondary School Classrooms. Australia: University of Tasmania, 2012.

[45] J. Hirsch, The Feedback Fix: Dump the Past, Embrace the Future and Lead the Way to Change. Rowman and Littlefield Publishers, 2017.

[46] L. Alderman, S. Towers and S. Bannah, "Student Feedback Systems in Higher Education: A Focused Literature Review and Environmental Scan," Quality in Higher Education, vol. 18, no. 3, pp. 261-280, 2012.

[47] S. Clarke, Formative Assessment in the secondary classroom London. UK: Hodder Stoughton, 2012.

[48] E. Pitt and L. Norton, "Now that's the Feedback I Want! Student's Reactions to Feedback on Graded Work and what they do with it,". Assessment and Evaluation in Higher Education, vol. 42, no. 4, pp. 499-516, 2017

[49] A. Forsythe and S. Johnson, "Thanks, but No-Thanks for the Feedback," Assessment and Evaluation in Higher Education, vol 42, no. 6, pp. 850-859, 2017.

[50] A. A. Omer and M. Abdularhim, "The criteria of constructive feedback: The Feedback that counts," Journal of Health Specialties, vol. 5, no. 1, pp. 45-48, 2017.

[51] B. Wisniewski, K. Zierer and J. Hattie, "The Power of Feedback Revisited: A Meta-Analysis of Educational Feedback Research," Frontiers in Psychology, vol. 10, pp. 1-14, 2020. 